\title{
Justificación de una justicia ambiental en Colombia
}

Abogado de la Universidad Externado de Colombia, especializado en Derecho Mineroenergético de la misma Universidad. Catedrático de la Universidad Surcolombiana.

Álvaro Hernando Cardona González

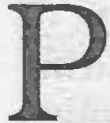

oco a poco se empieza a reflexionar en Colombia sobre las verdaderas causas del conflicto colombiano, que por descarte y por comparación con lo sucedido en otros confines de la Tierra, viene develándose, no tanto como originario en la pobreza (aunque sí alimentada y aupada por ella) como en la crisis institucional del Estado incapaz de hacer justicia efectiva y pronta.

Los conflictos internos de Guatemala, El Salvador y aún Nicaragua (aunque en este caso sí la dictadura de Somoza fue el origen y alimento de la. lucha armada) demuestran que en América Latina, más que la pobreza, las desigualdades que se notan en $\bullet$ el acceso a la justicia y la resolución efectiva de los litigios (lo que llamaremos justicia efectiva y pronta) es lo que genera más temprano que tarde los conflictos armados internos y obstruyen su solución cualquiera que ella sea.

Dentro de là ya reconocida y posicionada rama del derecho conocida como el derecho ecológico colombiano, existen a su vez diversos aspectos que chocan y se confunden con otros que los antecedieron. Uno de ellos, el de los procedimientos sancionatorios establecidos para cuando las autoridades requierăn imponer medidas preventivas o sanitarias y sanciones por infracción de la normatividad ambiental o ecológica, que requiere que quienes conocen de tales temas intenten determinar, aclarar o delimitar las discusiones sobre la existencia, validez e interpretación de las normas pertinentes, desde la óptica de su aporte a la solución del conflicto.

En el tema del proceso sancionatorio por violación de las normas sobre protección ambiental o sobre manejo de recursos naturales renovables, el trabajo de interpretación normativa tiene un ingrediente adicional de interés, dado que la Ley 99 de 1993 , para nosotros el segundo punto de quiebre en la normatividad ecológica, luego de la Lèy 23 de 1973, no incluyó un procedimiento propio sino que adoptó "provisionalmente" el que ya había establecido el Decreto Reglamentario 1594 de 1984 (consecuencia del primer quiebre normativo). Así, hoy contamos con una normatividad nueva pero coherente para la protección y manejo ecológico. 
con un procedimiento para imponer medidas preventivas o sanciones adoptado de un esquema normativo diferente, tal vez útil, pero no efectivo, hay que decirlo de una vez, para estos tiempos.

Procuraremos, entonces, primero explicar cuál es el procedimiento vigente para llevar a cabo la justicia ambiental en Colombia y justificar con ello y de manera didáctica, algunas reformas tanto al sistema como al procedimiento legalmente establecido dentro del Estado de Derecho y del debido proceso que contribuyan a optimizar la búsqueda de la equidad, al restablecimiento de los equilibrios con prontitud y a aclimatar los niveles de conflictividad colombianos.

\section{Síntesis de la legislación colombiana}

Actualmente, la Constitución Política de Colombia no sólo contiene varios artículos relaçionados de manera directa e indirecta con la protección ambiental y el deber del Estado y los ciudadanos para ello, sino que trae varios propugnadores por el desarrollo sostenible y estimulantes de una sana relación del hombre con su entorno (ecología) sino que aduce a la protección del medio ambiente desde tres ópticas: como derecho, como deber el Estado y como principio.

Cuando se expidió la Ley 99 de 1993 , el legislador colombiano entendió que la nueva estructura del poder público encargado de la gestión medio ambiental, debía estar precedida de instrumentos que tornaran eficientes los propósitos al momento de su expedición. Entre ellos, de unos poderes de policía que lograran precisamente dotar a las autoridades ambientales de facultades que complementaran las de fijar y ejecutar la política sectorial y, por el otro, de materializar las funciones de máximas responsables de la acción ambiental alcanzando el grado de atención necesario de la población.

Si no fuera por las potestades de policía que hoy tienen.nuestras autoridades ambientales, la normatividad sobre protección, conservación y recuperación del entorno humano no tendría objeto. Sobre este punto nos parecen oportunas las reflexiones del profesor de la Universidad Nacional de Colombia, Ricardo Sánchez quien afirma que la responsabilidad del derecho sobre el medio ambiente es creciente por la toma de conciencia de que las instituciones jurídicas y políticas han servido de soporte y han sido agentes concurrentes a la crisis. Sostiene, igualmente, que el derecho ha cumplido un papel sancionador de injusticias y ha velado las desigualdades y contradicciones a escala de las naciones y los pueblos. También sostiene que, en relación con la cuestión ambiental, los sistemas legales y las instituciones son sancionadores del derecho de propiędad privada, de los intereses del capital, de la preponderancia de los centros metropolitanos; por lo tanto, la refléxión, crítica y diseños al interior del derecho como disciplina y técnica de acción social y política están en reconocer esta situación.

No nos debe extrañar, entonces, la relación que surge entre el derecho policivo, preventivo o sancionador y el 
derecho ecológico. ¿Por qué no aceptar la existencia de instrumentos sancionadores en manos de las autoridades administrativas encargadas de la gestión medio ambiental, cuando de las relaciones del hombre con los recursos naturales, sean ellos renovables o no (para el caso no importa), surgen relaciones de las cuales se pueden derivar responsabilidades en todas sus formas, según tuvo el autor de este escrito, oportunidad de exponerlo durante las Segundas Jornadas internacionales en Derecho del Medio Ambiente que se organizaron por iniciativa de la Universidad Externado de Colombia en Bogotá, en agosto de 2000? En el encuentro académico indicado, se planteó que la novedad y característica del derecho ambiental, de ser multidisciplinario, lo enfrenta por doquier con retos jurídicos que surgen de la aplicación de las normas a los hechos que supuestamente generaron la necesidad đe su regulación. En los países que adoptaron el sistema romano, hoy conocido como del civil law, ya es frecuente que el legislador, muchas veces $\sin$ consultar la realidad o ensayar la aplicación material de un proyecto normativo, expida o adopte reglas de conducta que luego se dificultan aplicar frente al supuesto de hecho que lo exige. De ahí que para muchos, las reglamentaciones novedosas, recientes, de poca trayectoria jurisprudencial, se aprecian como un conjunto de buenas intenciones.

Por otro lado, de conformidad con el numeral 2 del artículo 11 de la Declaración Universal de los Derechos Humanos, aprobada por la Asamblea General de las Naciones Unidas el 16 de diciembre de 1948, "Nadie será condenado por actos $\mathrm{u}$ omisiones que en el momento de cometerse no fueron delictivos según el derecho nacional o internacional. Tampoco se impondrá pepa más grave que la aplicable en el momento de la comisión del delito". Fácilmente se encuentra que esto va en armonía con los artículos 29 y siguientes de nuestra Constitución Política que procuran el denominado principio del debido proceso.

Confiamos que la legislación ambiental en Colombia haya demostrado, luego del nuevo marco constitucional generado desde la Constitución de 1991, que si bien estaba en mora de adquirir estatus de rama autónoma del derecho, llega luego de comprobar su necesidad como elemento articulador efectivo entre la sociedad y su entorno garantizando las condiciones mípiimas para la evolución, desarrollo y progreso de la humanidad como especie. De ahí que para algunos el derecho ambiental ha superado el criterio conservacionista adquiriendo otro de equilibrio. En efecto, apoyados en el principio 1 de la Declaración de Río de Janeiro sobre Ambiente y Desarrollo de 1992 (Conferencia UNCED - 1992) cuando expresa: "Los seres humanos constituyen el centro de las preocupaciones relacionadas con el desarrollo sostenible. Tienen derecho a una vida saludable y productiva en armonía con la naturaleza", algunos sostienen que ya es hora de superar muchas desigualdades e injusticias, sobre todo de cara a las necesidades de desarrollo de las poblaciones más pobres, que dejemos de pensar sólo en la conservación y protección muchas veces a ultranza y "socialicemos" las verdaderas necesidades de recursos naturales. 
Estamos de acuerdo en que éste sea el marco dentro del cual se producen actos jurídicos, sucesos generados por el hombre con repercusiones jurídicas de interés para él y su sociedad, que ameritan generar medidas preventivas y sanciones para quienes actúen por fuera del ordenamiento en sus relaciones con los recursos naturales renovables y el medio ambiente; medidas y sanciones que requieren de un procedimiento a través del cual se garanticen todos los principios que soportan el llamado debido proceso.

Las atribuciones de policía en el derecho ecológico

Quiso Winston Churchill significar lo inútil que es para un Estado no contar con instrumentos de fuerza que hagan posible la sujeción de sus ciudadanos con una frase parecida a: "la balanza de Temis la representan las Cortes de los Lores aplicando la voluntad soberana; su espada la representa la flota del Imperio". De muy poco serviría contar nuestro país. con el Código Nacional de Recursos Naturales y el Medio Ambiente más reconocido del mundo, si no existieran procedimientos sancionatorios para aplicar a quienes infrinjan dichas disposiciones.

En Colombia, por lo anterior, la Constitución Política, las leyes y los reglamentos han otorgado a las autoridades administrativas una serie de atribuciones a través de las cuales limitan, mediante la expedición de medidas generales o particulares, la libertad de las personas, con el fin de que sus actividades se adecuen al mantenimiento de unas condiciones mínimas que hagan posible la convivencia social, es decir, la conservación del orden público, que constituye el objeto del llamado "Poder de Policía". Cuando el "Poder de Policía" se determina en cabeza de la administración, se le denomina "Poder de Policía Administrativa"; entonces, las autoridades de policía, a través de los llamados "medios de policía", aseguran la tranquilidad ciudadana $y$, en tal virtud, entre sus competencias está la de controlar y fiscalizar las diferentes actividades que desarrollan los particulares. Por ello, se explica que para realizar actividades que puedan causar deterioro a los recursos naturales renovables o al medio ambiente se pueda requerir la obtención de licencia, permiso o autorización de tipo ambiental por la autoridad administrativa.

Ya habíamos mencionado que actualmente, gracias a la Ley 99 de 1993 (Título XII, artículos 83 y siguientes) se viene aplicando un procedimiento tomado de norma anterior a ella pero que ha sido muy útil. Tanto, que a pesår de que la intención de la Ley 99 de 1993 era el de fijar provisionalmente un procedimiento para imponer las medidas sanitarias o preventivas y sanciones por incumplimiento a la normatividad, mientras se expedía una disposición al amparo del nuevo régimen constitucional y legal, hasta ahora en nada se ha modificado.

Efectivamente, el parágrafo 3 del artículo 85 de la Ley 99 de 1993, establece que para la imposición de las medidas y sanciones de que trata ése mismo artículo, "se estará al 
procedimiento previsto por el Decreto 1594 de 1984 o al estatuto que lo modifique o sustituya", lo cual, insistimos, no ha sucedido.

Pero" no es fácil la aplicación del procedimiento así como está previsto justamente por el aparente desentono de tin procedimiento expedido con anterioridad a la Constitución y a la nueva estructura del poder público encargada de la gestión medio ambiental en Colombia.

Se ha reconocido que son normas sustanciales las que consagran tanto obligaciones como prohibiciones en materia ambiental, que son numerosas y que no existe un código que las compile; sin embargo, su incumplimiento da lugar a la imposición de sanciones. Tales comportamientos pueden consistir, en delitos, en contravenciones de policía (ordinarias o especiales) o en contravenciones administrativas ambientales. Y ellos_pueden traer sanciones consigo, que pueden además aplicarse simultánea o individualmente.

Lo que sí es muy fácil, es darle la connotación de atribuciones de policía a las que gozan, desde la expedición de la Ley 99 de 1993, ciertas autoridades ambientales. Primero, porque la misma Ley denomina "de las sanciones y medidas de policía" al Título XII de la Ley 99 de 1993; empezando por tratar sobre las "atribuciones de policía" en su artículo 83, el primero del mismo.

No sobra además subrayar que no hay lugar a confundir las acciones policivas administrativas con otras, como las civiles o penales, ya que la propia Ley 99 de 1993 se encarga de advertir que cuando fuere el caso, frente a violaciones de las normas sobre protección ambiental o manejo de los recursos naturales renovables, éstas se denunciarán ante las autoridades competentes para que inicien las investigaciones penales respectivas (artículo 84) y que las sanciones aplicables, por vía administrativa (las del numeral 1 del artículo 85 de la Ley 99), se aplicarán sin perjuicio del ejercicio de las acciones civiles y penales a que haya lugar (parágrafo 2 del artículo 85). Incluso, no habría confusión con las acciones disciplinarias, cuando se trate de conductas de los servidores públicos, por la expresa remisión que el parágrafo 4 hace a la Ley 47 de 1993 (ver artículo 30), aun cuando esto es cosa distinta.

El papel del debido proceso en los procedimientos ambientales

La ritualidad es infaltable en un sistema rígido como el que Colombia escogió; respetuoso de las letras y su significado como paradigma del derecho. Por ello, en el derecho ecológico no podía faltar un procedimiento y menos, cuando la Ley 99 de 1993 unificó los criterios, ámbitos y competencias de las medidas preventivas y de las sanciones que pueden imponerse por violación de las normas ecológicas.

Ciertamente y como hemos visto, la Ley 99 de 1993 dispuso en uno de los Parágrafos del artículo 85 que para imponer las sanciones o medidas preventivas (antes "sanitarias"), las autoridades ambientales deben seguir el procedimiento señalado en el 
Decreto 1594 de 1984, reglamentario del Código Nacional de los Recursos Naturales Renovables y de Protección al Medio Ambiente.

Algunos pusieron en duda la posibilidad de que tal disposición estuviera sujeta al ordenamiento colombiano, especialmente después de expedida la Constitución Política de 1991, que ordena que las normas de procedimiento se expidan por el legislador y ya no sea posible su delegación. En otras palabras, como ya lo habíamos dicho, que las normas del procedimiento ambiental se contuvieran en un Código. Razón por la cual la Corte Constitucional, al ser exigida al respecto, tuvo que pronunciarse en sentencia de constitucionalidad C-710 de 2001 , en la cual sostuvo que si bien es cierto es necesario que sea el legislador el que se pronuncie expresamente sobre cuál debe ser el procedimiento a seguir en cada caso que se requiera imponer una sanción o medida preventiva, eso ha ocurrido, sólo que el legislador al expedir la Ley 99 de 1993 no lo hizo desarrollando todo un procedimiento expreso sino por vía de lo que la Corte denominó "remisión"; es decir que aunque se remitió a un procedimiento contenido en Decreto Reglamentario y anterior a la Constitución y a la Ley que lo menciona, ésa y no otra es justamente la voluntad del legislador, del competente constitucional.

\section{Ecología y paz}

Consideramos conveniente traer a colación apartes de un escrito reciente del señor Juan Mayr Maldonado, entonces Ministro de Medio Ambiente colombiano publicado en la revista Semana (marzo 19 - 26 No. 985; Bogotá 2001. p. $60-63$ ) en el que reflexiona diciendo, "La paz y el desarrollo sostenible durante las próximas décadas podrían conducir a la justicia social y al buen manejo ambiental". Compartimos con el ex ministro que, dada la importancia que la Constitución Política le ha dado a la fórmula def desarrollo sostenible para administrar los recursos naturales que hacen posible el equilibrio ecológico en el crecimiento económico, seguramente son muchos los factores ambientales los que inciden en nuestra concepción de las cosas, en nuestro comportamiento violento y en la búsqueda y aceptación de formas civilizadas de resolver nuestros conflictos.

Concluimos con una reflexión más de Mayr Maldonado, "Los instrumentos jurídicos e institucionales están dados pero definitivamente el futuro de Colombia está íntimamente ligado a la paz. Todas las acciones que se emprendan hoy para garantizar la protección y el manejo sostenible del patrimonio natural se constituirán en la base para la construcción de un futuro próspero y pacífico para las generaciones venideras". $\infty$ 